\title{
Designing Tourism Routes From Tourism Behaviors and Needs of the Tourists in Chaiyaphum Province, Thailand
}

\author{
Thudsanaiyawan Doungmala, Noppamash Suvachart \\ Khon Kaen University, Khon Kaen, Thailand
}

\begin{abstract}
The aim of this research was to study tourism behaviors and needs for tourism of Thai tourists in Chaiyaphum province in order to bring their tourism behaviors and needs to design tourism routes which are suitable and able to meet the needs of tourists. Questionnaire survey was used to collect data from 400 tourists who traveled to visit Chaiyaphum province. Accidental sampling technique was applied to select the sample. Percentage, mean, and standard deviation were used to analyze the data. The research results revealed that tourists were mostly male with 26-40 years of age and aimed to use spare time with their own families or friends. Most tourists traveled with their families (husband/wife/son/daughter), because they attach great importance to creating a good relationship with the members of their families in order to show their love and warmth among members within the families. Most tourists took only one day to visit Chaiyaphum province (travel there and back in a day). Tourists' needs for visiting tourism places in Chaiyaphum province were as follows: (1) to visit popular and famous tourism places; (2) to visit natural tourism places; and (3) to visit historical and cultural tourism places.
\end{abstract}

Keywords: tourism behaviors, tourism needs, tourism routes

\section{Introduction}

Tourism is an important economic sector of the country, because the revenue from foreign tourists accounted for $10 \%$ of gross domestic product (Tachaphaiboo, 2014). Income and expenditure of the people, however, had decreased due to world economic crisis. This event had affected the production and service sectors of all countries in the world. Department of Tourism (2011) said that although Thailand was affected by various crises such as political instability, economic recession, and higher price of gasoline, the amount of Thai tourists in Thailand had steadily increased.

Consequently, Thai people should be to travel within country in order to support domestic tourism and create domestic tourism market. Thailand should not depend on revenue from foreign tourists. Domestic tourism can stimulate cash flow within the country and help Thai economy recover from the recession. Domestic tourism brings revenue to local people. According to national tourism plan 2012-2517, there had been a growing trend of the amount of Thai tourists who intended to travel within country, because Thai government had a policy to support domestic tourism which incurs money circulation within the country and income distribution to local community.

Thudsanaiyawan Doungmala, Ph.D. candidate, Faculty of Management Sciences, Khon Kaen University. Email: boo_307@hotmail.com.

Noppamash Suvachart, associate professor, Faculty of Management Sciences, Khon Kaen University. 


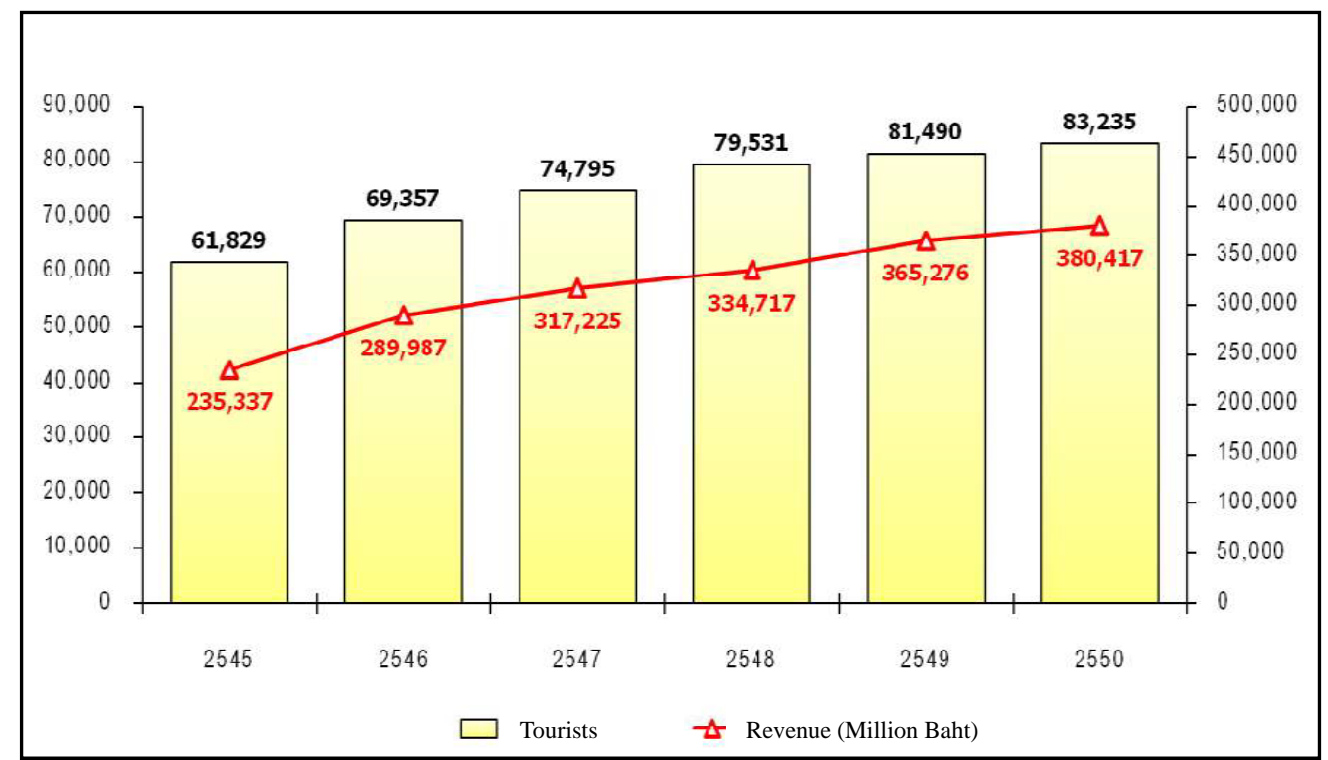

Figure 1. The amount of Thai tourists and revenue from Thai tourists for the years of 2002-2007. Source: Ministry of Tourism and Sports (2011).

Tourism route selection of tourists was influenced by their friends who gave reliable advice (Buathong, 2011). Searching information of tourism was influenced by their friends, relatives, and families (National Statistics, 2012). Tourism route selection was also influenced by the tourism companies or the public relation media provided by public and private organizations. Tourism routes were organized by responsible organizations without studying the real behaviors and needs of tourists.

Chaiyaphum province is located in the northeast region of Thailand. Its area is connected to central region and northern region which are the potential natural tourism places. Chaiyaphum has the potential tourism places which are able to attract tourists to visit Chaiyaphum province all over the year.

According to the facts and problems mentioned above, we are interested in studying tourism routes with the aim of investigating tourism behaviors and needs of Thai tourists in order to provide information for designing tourism routes which are consistent with the needs of tourists and can be used to support domestic tourism, economy, money circulation, job and income creation, and improvement of quality of life of the people in local community.

\section{Objectives}

The objectives of this paper are to study the tourism behaviors and needs for tourism of Thai tourists visiting Chaiyaphum province and design tourism routes which are suitable for tourists.

\section{Research Problems}

The research problems of this paper are as follows:

(1) How were the tourism behaviors and needs for tourism of Thai tourists visiting Chaiyaphum province?

(2) How should be the tourism routes for Thai tourists in Chaiyaphum province?

\section{Literature Review}

To design tourism paths from the behaviors and needs for tourism of tourists in Chaiyaphum province, we had reviewed the related literature concerning tourism behaviors and tourism routes. 


\section{Tourism Behaviors}

Factors resulting in tourism behaviors include: (1) economic factors: specific characteristic of tourism industry is that tourists must travel to purchase tourism goods and services at the places where the goods and services were produced. The important economic factors that should be considered consist of income and exchange rate; (2) factors affecting decisions to travel: factors that can be used for decisions to travel such as personal interest, travel planning, time, near tourism places, dominance of tourism place, and the readiness of tourism places; (3) pattern of travel: each travel has a different pattern; and (4) tourism safety: usually, when tourists travel to anyplace, they are always concerned with safety, therefore, safety problem also affects the number of tourists (Wongvanich, 2003).

\section{Tourism Routes}

Mancini (1990) said that any person who plans about tourism routes must consider the following factors: (1) date determination: One must consider the distance and number of tourism places to visit; (2) target customers: If target customers are old people, the period of travel should be short, places to visit should not be so many, the old customers should not travel by bus for so long time, and schedule should be flexible; (3) distance: Traveling for a long period always makes tourists feel tired, and if the target tourism place is far away, time will be wasted; (4) entertainment: Entertainment activities, such as the show, should be provided for tourists; (5) shopping: Time for shopping should be provided for tourists, because buying gifts for their relatives is the tradition of Thai tourists; (6) hotel location: Selection of hotels should consider a good location, if the selected hotel is in the middle of city, it will encounter traffic jam problems and take so long time for tourists to travel further to other areas. It would be the right selection of hotel which is in the middle of the city when tourists have a plan to purchase some goods or services in the city, otherwise, the hotel which is outside the city should be selected instead; (7) sightseeing: The sightseeing should be a gas station or food store so that tourists can take a rest, go to the toilet, purchase snack, water, or coffee; and (8) restaurant: It is the fact that the food that is the most expensive does not always come with the best taste and quality, therefore, selection of restaurants should consider quality, cleanness, and suitability.

\section{Findings}

Questionnaire survey was used to collect data from 400 Thai tourists who came to visit Chaiyaphum province. Accidental sampling was applied to select the sample. The results can be summarized as follows.

\section{Tourists' Gender}

Of the 400 respondents with completed surveys, approximately 213 were male which accounted for $53 \%$ and 187 were female which accounted for $47 \%$ (see Figure 2).

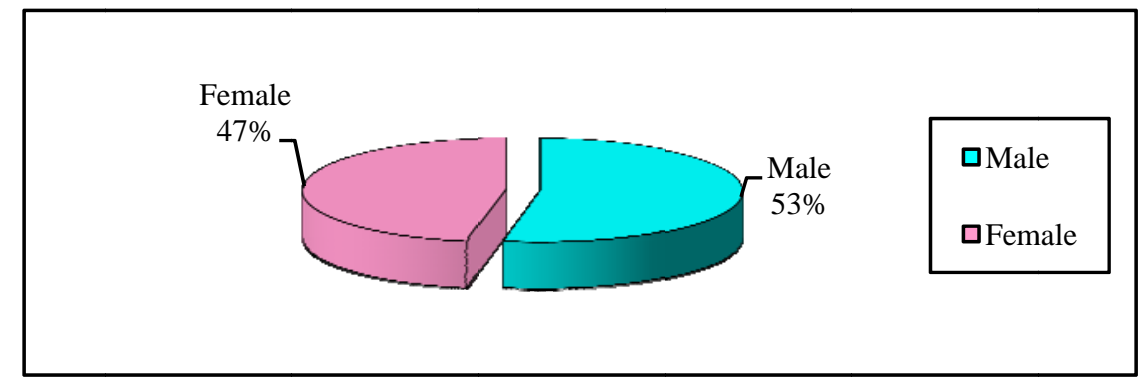

Figure 2. Percentage of tourists classified according to gender. 


\section{Tourists' Age}

Of the 400 respondents, 143 respondents aged between 26 and 40, which accounted for 36\%, 114 respondents aged between 41 and 60, which accounted for 28\%, 83 respondents aged between 15 and 25, which accounted for 21\%, followed by 60 respondents who aged 61 and more, which accounted for 15\% (see Figure 3).

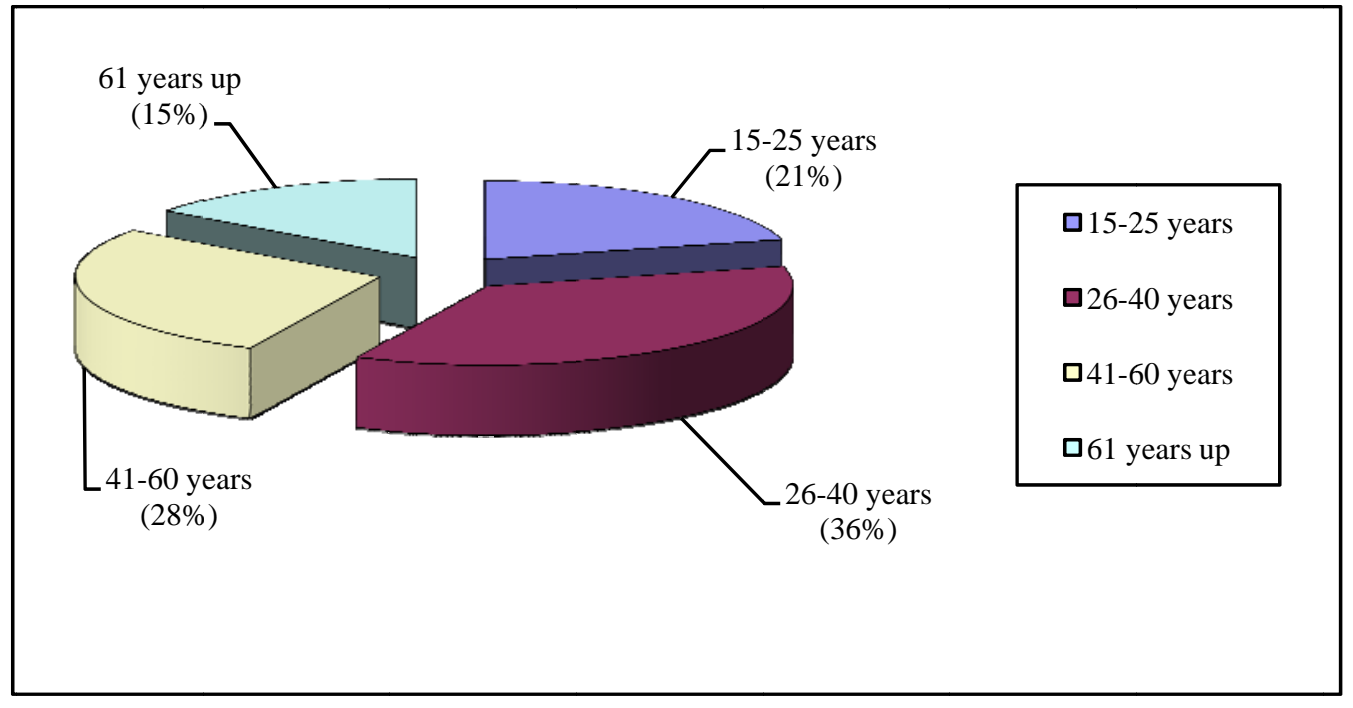

Figure 3. Percentage of the respondents classified according to age group.

\section{Tourism Purposes}

The number of tourists could be classified based on tourism purposes shown in Figure 4. Among the 400 respondents, 250 (about 62\%) of the tourists had traveled to visit tourism places with the purpose of spending spare time with families or friends, 129 (about 32\%) of the tourists had traveled to visit tourism places with the purpose of leisure on holidays, 10 (about 3\%) of the tourists had traveled to visit tourism places with the purpose of conducting day activities, eight (about 2\%) of the tourists had traveled to visit tourism places with the purpose of studying the local culture, and finally, three (about 1\%) of the tourists had traveled to visit tourism places with the purpose of doing other activities, such as making a merit.

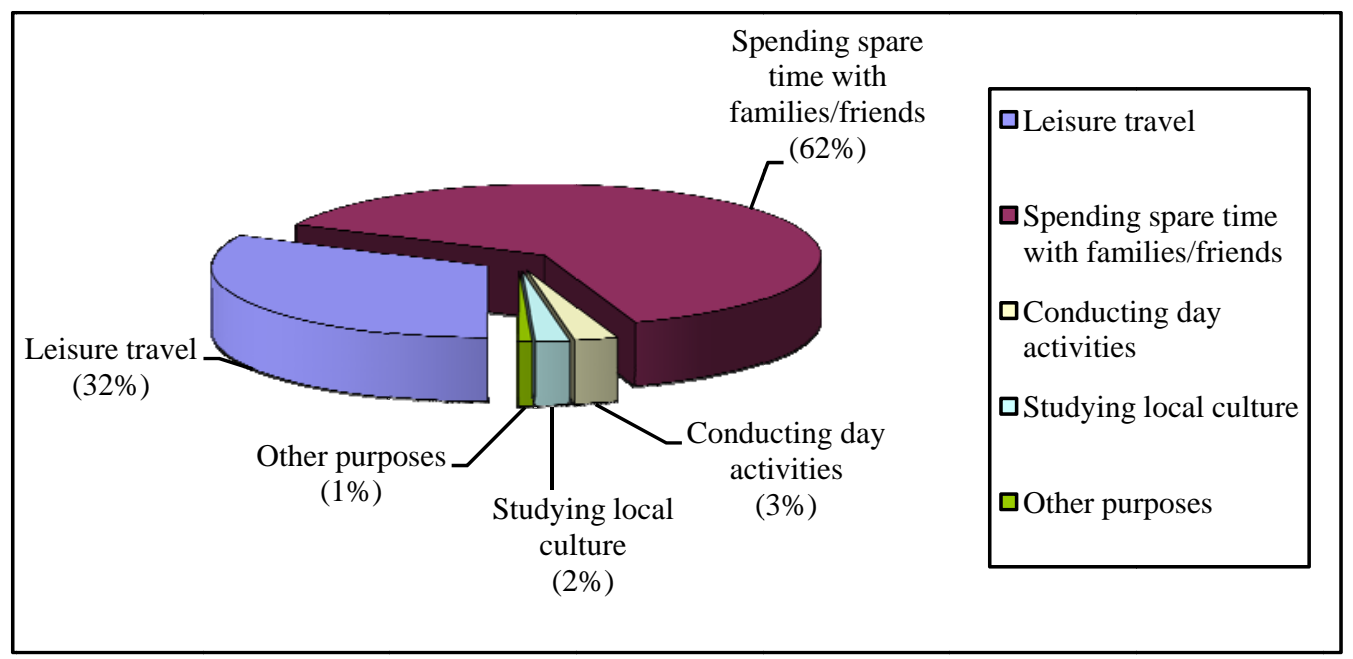

Figure 4. Percentage of the respondents classified according to tourism purposes. 


\section{Accompanied People}

When tourists traveled to visit tourism places, 206 tourists (about 51\%) were accompanied by the members of their families (husband/wife/son/daughter), 162 tourists (about 41\%) were accompanied by friends, 25 tourists (about 6\%) were accompanied by parents, and finally, seven tourists (about 2\%) had traveled alone (see Figure 5).

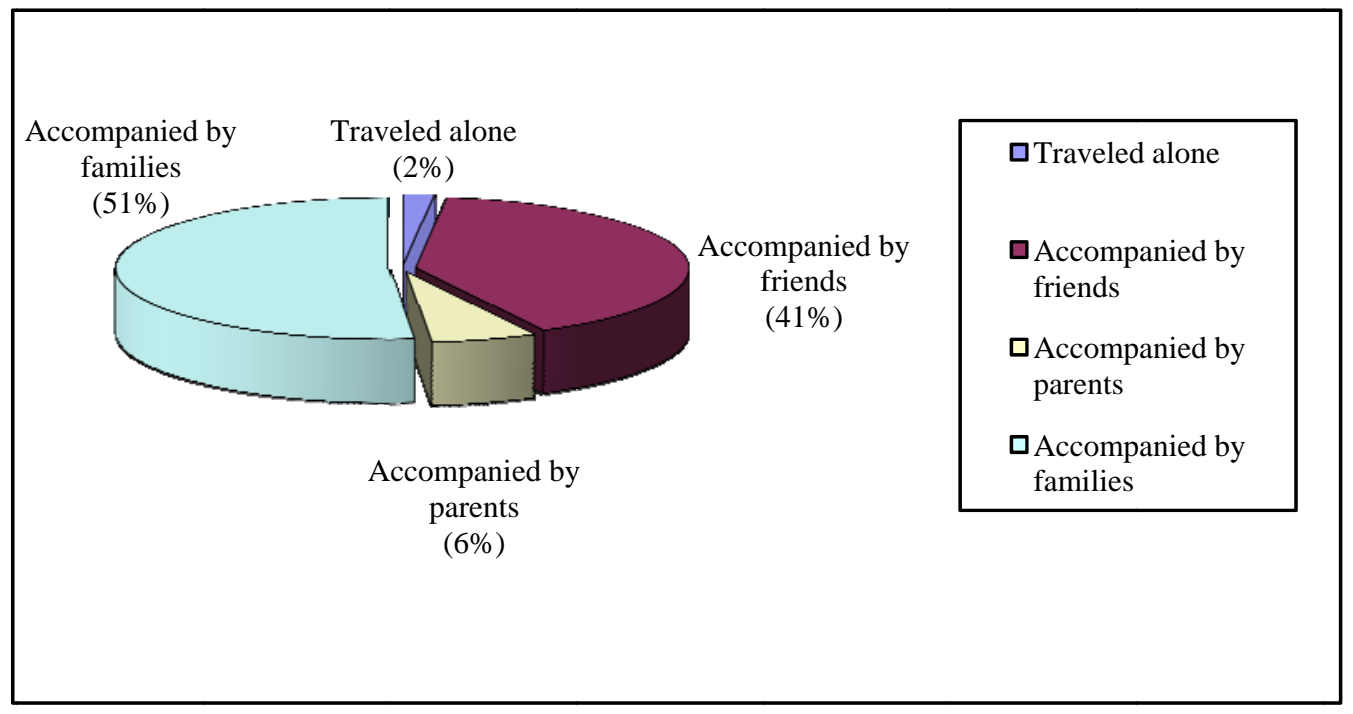

Figure 5. Percentage of the respondents classified according to accompanied people.

\section{The Length of Stay}

The period of time which tourists spend in a recreation is one of the most important factors influencing their total expenditures. The research results revealed that 250 tourists (about 62\%) had the length of stay for only one day, 147 tourists (about 37\%) had the length of stay for 2-3 days, three tourists (about 1\%) had the length of stay for 4-5 days, however, there was no tourist who had the length of stay for more than six days (see Figure 6).

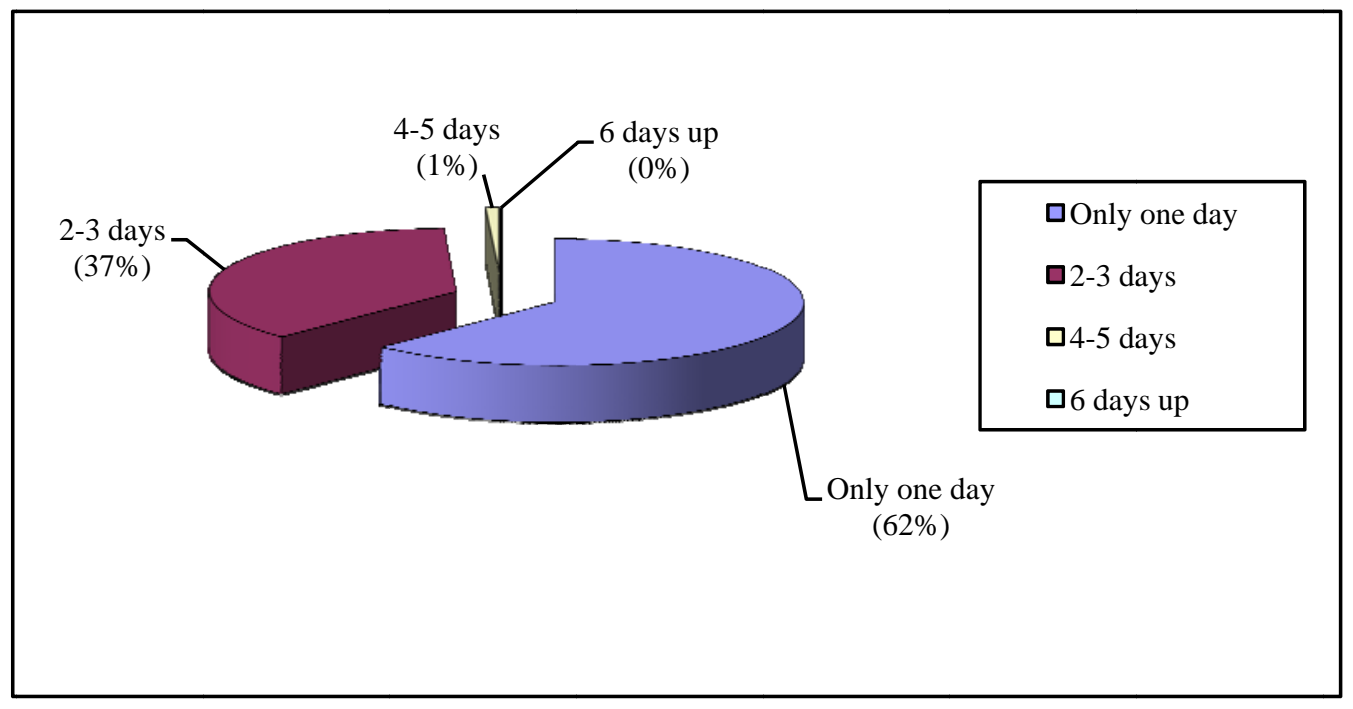

Figure 6. Percentage of the respondents classified according to length of stay. 


\section{Tourists’ Need Hierarchy}

The need of tourists who had traveled to visit Chaiyaphum could be ranked as follows: (1) the first order: Most tourists wanted to visit popular tourism places in Chaiyaphum province; (2) the second order: Tourists wanted to visit natural tourism places; and (3) the third order: Tourists wanted to visit historical and cultural tourism places (see Figure 7).

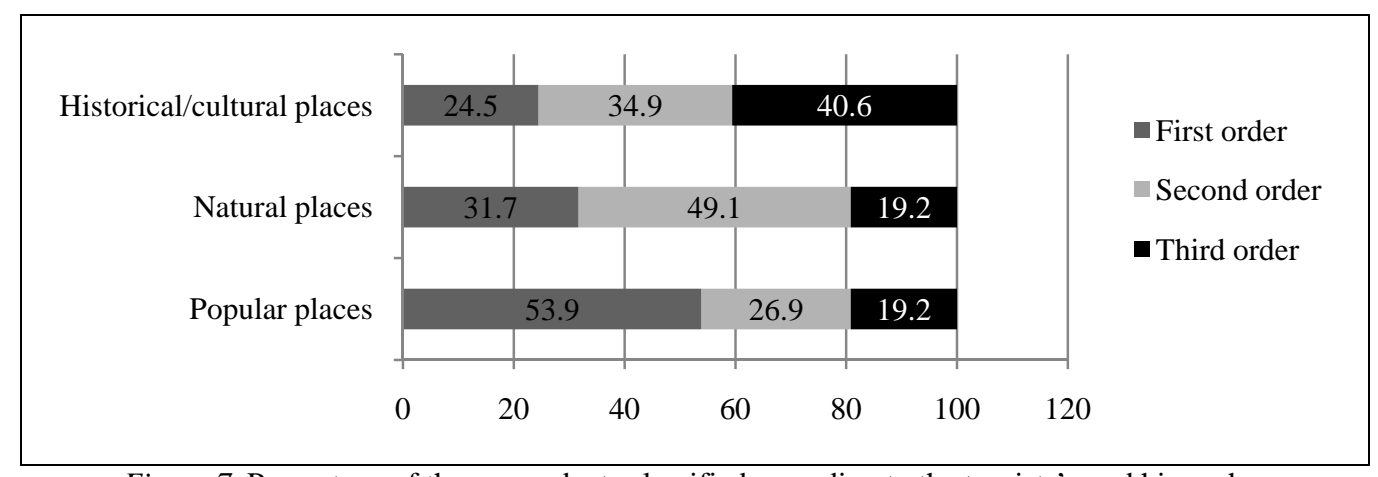

Figure 7. Percentage of the respondents classified according to the tourists’ need hierarchy.

\section{Discussion}

The results from studying the behaviors and needs for tourism of Thai tourists who had visited Chaiyaphum province revealed that tourism places in Chaiyaphum are mostly natural places which bring about the day activities for tourists, such as forest walking to study the nature, seeing the birds, taking the photos, pitching the tent, sightseeing. Tourists who came to visit Chaiyaphum province were mostly male and they aged between 26 and 40. This group of tourists is usually fond of adventures and challenges. They, in addition, were strong, healthy, and able to do the day activities. They attached great importance to their families. As for tourists who were single, they attached great importance to their friends. Therefore, most tourists wanted to spend their spare time with their families or friends.

Most tourists who traveled to visit Chaiyaphum province came with their families (husband/wife/son/daughter), because these tourists attached great importance to creating a good relationship with the members of their families and started to live together with their husbands/wives (Papalia \& Olds, 1995). Tourists attached great importance to creating love and warmth among the members of their families. They emphasized the importance of doing activities within the family during tourism, however, they spent only one day to visit tourism places in Chaiyaphum province (came in the morning and went back in the evening). Because Chaiyaphum province is near to Bangkok, Nakhonratchasima, and Khonkhan provinces, tourists always passed Chaiyaphum province to stay in those provinces which have bigger sizes and are able to offer them more qualified facilities and services.

Tourists' needs to travel to visit tourism places in Chaiyaphum province could be ranked in order of importance as follows: (1) Tourists wanted to travel to visit popular and famous tourism places once in a lifetime; (2) Tourists wanted to visit natural tourism places, because there are a lot of natural places in Chaiyaphum province; and (3) Tourists wanted to visit historical and cultural tourism places. In the ancient time, Chaiyaphum province was occupied by Khom people, who had created the historical stories and buildings for the present generation. Custom and tradition of Chaiyaphum, which is a province in northeastern region, in addition, are dominant and attractive to tourists. 


\section{Conclusions}

The results from studying the behaviors and needs of Thai tourists who came to visit Chaiyaphum province revealed that designing tourism routes must attach great importance to tourists' families. Because most tourists aged between 26 and 40 and attached great importance to creating a good relationship with the members of their families and love and warmth among the members of their families, therefore, tourism activities which emphasized creating a good relationship among the members of their families should be designed.

Because most tourists had spent only one day to visit tourism places in Chaiyaphum province, tourism activities for tourists who spent only one day in Chaiyaphum province should be designed to satisfy them. In addition, tourism routes for tourists who spent 2-3 days to stay in Chaiyaphum province should be offered and designed in order to provide additional choices and stimulate tourists to spend additional days in Chaiyaphum province which results in their additional expenditures including the additional income of local people. Tourists' needs for visiting tourism places in Chaiyaphum province were as follows: (1) to visit popular and famous tourism places; (2) to visit natural tourism places; and (3) to visit historical and cultural tourism places.

In the process of designing tourism routes for tourists, therefore, tourism behaviors and needs of tourists must be studied so that tourism needs would be designed properly for different groups of tourists.

\section{References}

Buathong, J. (2011). The view of trip advisor on tourists and tourism management in the age of change in technology, society, and economy. Retrieved from http://www.etatjournal.com/web/menu-read-web-etatjournal/menu-2011/menu-2011-apr-jun/317-22554-trip-advisor Department of Tourism. (2011). The national tourism development plan 2012-2016. Retrieved from http://www.tourism.go.th Mancini, M. (1990). Conducting tours. Australia: Delmar Publisher.

Ministry of Tourism and Sports. (2011). Tourism statistics 2010. Retrieved from http://www.tourism.go.th/2010/th/home/index.php

National Statistics. (2012). Surveying tourism behavior of Thai people for the year 2012. Retrieved from http://service.nso.go.th/nso/nsopublish/themes/files/TravelExec55.pdf

Papalia, E. D., \& Olds, W. E. (1995). Human development. New York, N.Y.: McGraw-Hill.

Tachaphaiboo, P. (2014). Direction of travel Thailand 2014. Retrieved from http://www.banmuang.co.th/2014/01

Wongvanich, W. (2003). Tourism geography (2nd ed.). Bangkok: Thammasat University. 